\begin{abstract}
THEREAN THEK@REAN SOCIETY S@CIETY

Journal of Electrochemical Science and Technology

\section{Layered Nickel-Based Oxides on Partially Oxidized Metallic Cop- per Foils for Lithium Ion Batteries}

\author{
Young-Hoon Chung, Sun Ha Park, Hyun-Sik Kim, and Yung-Eun Sung ${ }^{\dagger}$ \\ World Class University (WCU) Program of Chemical Convergence for Energy \& Environment (C2E2), School of Chemical \\ and Biological Engineering, Seoul National University (SNU), Seoul 151-744, Korea
}

ABSTRACT :

Thin film electrodes have been intensively studied for active materials and current collectors to enhance the electrochemical performance. Here, porous structures of nickel-based oxide films, consisting of nickel oxide and copper (II) oxide, which was derived from the copper substrate during the annealing process, were deposited on metallic copper foils. The half-cell tests revealed excellent capacity retention after $80^{\text {th }}$ charge/discharge cycles. Some films showed an excess of the theoretical capacity of nickel oxides, which mainly originate from partially oxidized copper substrates during annealing. These results exhibit that both a preparation method of an active materials and partially oxidized current collectors could be important roles to apply thin film electrodes.
\end{abstract}

Keywords : Nickel Oxides, Copper Oxides, Current Collectors, Anode, Lithium Ion Batteries

Received December 3, 2011 : Accepted December 27, 2011

\section{Introduction}

The decreasing size of electronic devices has focused increasing attention on thin film batteries as an on-chip power supplier. Like the general types of lithium ion batteries, thin film batteries use an anode and cathode. In particular, the anode is composed of a current collector and an active material that reacts with lithium ions directly. Most preliminary approaches focused on current collectors ${ }^{1-3)}$ or active materials ${ }^{4-8)}$ separately. Moreover, previous reports used tedious deposition procedures, such as electrodeposition, ${ }^{1,2,6)}$ sputter deposition $^{4,7,8)}$ and electrostatic spray deposition ${ }^{5)}$ etc., to deposit the films.

In active materials, there has been considerable effort to replace the graphite (theoretical capacity: $372 \mathrm{mAh}$ $\mathrm{g}^{-1)}$ used commercially with an alternative one with a high energy density. Poizot et al. ${ }^{9)}$ reported that transition metal oxides, such as $\mathrm{NiO}, \mathrm{CoO}, \mathrm{FeO}$ and $\mathrm{CuO}$,

${ }^{\dagger}$ Corresponding author. Tel.: +82-2-880-1889

E-mail address: ysung@snu.ac.kr have high electrochemical capacity primarily from the decomposition of $\mathrm{Li}_{2} \mathrm{O}$ by the catalytic activity of the nano-sized transition metals that can be written as: $\mathrm{M}_{\mathrm{x}} \mathrm{O}_{\mathrm{y}}+2 \mathrm{y} \mathrm{Li} \mathrm{i}^{+}+2 \mathrm{y} \leftrightarrow \mathrm{y} \mathrm{Li} \mathrm{L}_{2} \mathrm{O}+\mathrm{x} \mathrm{M}$. Among the transition metal oxides, nickel based oxides have been studied extensively as the anode materials of lithium ion batteries due to their relatively lower cost than other transition metals. ${ }^{10)}$ Despite the high capacity and lower cost, nickel based oxide electrodes cannot be commercialized due to their low initial coulombic efficiency and poor capacity retention during charge/discharge process. ${ }^{9)}$ In particular, thin film electrodes composed of nickel based oxides have been studied extensively to improve electrochemical performance using various fabrication methods, such as pulsed laser ablation (PLA) ${ }^{11)}$ vacuum thermal evaporation, ${ }^{12)}$ chemical bath deposition (CBD). ${ }^{10)}$

This paper reports film electrodes with good electrochemical performance containing both active materials, i.e., nickel-based oxides, with suitable reactivity toward lithium ions and oxidized current collectors, i.e., copper oxides, which were formed during the heat treatment 
process. A convenient fabrication method was used involving the deposition of nickel-based oxides film electrodes on metallic copper foils using simple CBD method with subsequent heat treatment in air to convert the precursors to oxidized species. Because of the particular properties of the chemical solution, which was prepared by a specific sol-gel method, the films had a porous layered structure with particular advantages to electrodes in lithium ion batteries. The electrodes exhibited good electrochemical reactivity with high capacity retention. In addition, the properties of partially oxidized copper foils were examined at different temperatures ranging from $100^{\circ} \mathrm{C}$ to $300^{\circ} \mathrm{C}$. The oxidized films on the surface showed different surface morphologies according to the heat treatment temperature used. The temperature for the formation of continuous films with sufficient electrochemical capability for partially oxidized metallic copper foils was examined.

\section{Experimental}

Precursors of nickel-based oxides were prepared using a sol-gel method reported elsewhere. ${ }^{13)}$ Nickel diacetate tetrahydrate $\left(\mathrm{Ni}\left(\mathrm{CH}_{3} \mathrm{COO}\right)_{2} \cdot 4 \mathrm{H}_{2} \mathrm{O}\right.$; Aldrich, $99.8 \%$ ) was used as the nickel source in a solvent containing 2-(dimethylamino)ethanol $\left(\left(\mathrm{CH}_{3}\right)_{2} \mathrm{NH}\left(\mathrm{C}_{2} \mathrm{H}_{4} \mathrm{OH}\right)\right.$; Aldrich, $99.5+\%)$ and deionized(DI) water at a 1:1 volumetric ratio. The solution was aged for 2 days in air. The electrodes were fabricated using a dip-coater (Kwanghak Mechanical Eng. Co.) on copper foils (Nihonseihaku Co., 99.98\%) and coated 1 (sample 1), 2 (sample 2) and 3 times (sample 3). The following dipping conditions were used. Copper foils were dipped in the prepared solution for 8 minutes and withdrawn at a rate of $1.82 \mathrm{~cm} \mathrm{~min}^{-1}$ with the appropriate humidity control. The detail dipping conditions are reported in ref. 13. The pre-annealed electrodes were dried in an $80^{\circ} \mathrm{C}$ oven. The deposited electrodes were annealed in a tubular type furnace under a constant flow of compressed air at $300^{\circ} \mathrm{C}$ and a heating rate of approximately $5^{\circ} \mathrm{C} \mathrm{min}^{-1}$ for 3 hours, and cooled to the room temperature. The post-annealed samples were analyzed and applied to the anode of lithium ion batteries. The final amounts of deposited active materials are 3.3, 4.6, and $5.3 \times 10^{-4} \mathrm{~g} \mathrm{~cm}^{-2}$, respectively. For further investigation of the electrochemical reaction of partially oxidized copper foil, the bare copper foils were heat treated at different temperatures $\left(100,150,200,250\right.$, and $\left.300^{\circ} \mathrm{C}\right)$ at the same heating rate $\left(5^{\circ} \mathrm{C} \mathrm{min}{ }^{-1}\right)$ for 3 hours in the flow of compressed air. None of the post-annealed samples were further treated.

$\mathrm{X}$-ray diffraction (XRD) was carried out with a $\mathrm{D} /$ max-RC, Rigaku diffractometer to determine if there was full oxidation of the substrate. Field emission-scanning electron microscopy (FE-SEM; SUPRA 55VP, Carl Zeiss and JSM-7000F, JEOL) was used to examine the surface and cross-section of the electrodes. The constituents of the electrodes and the valence of metals were examined by X-ray photoelectron spectroscopy (XPS; Sigma probe, Thermo) in the ultra-high vacuum chamber $\left(<5 \times 10^{-10}\right.$ mbar $)$ with the electron gun $(15 \mathrm{kV})$.

For the electrochemical tests, a coin typed (CR 2016) half-cell was prepared in a glove box filled with argon. The counter electrode was a sufficient amount of lithium metal foil with a polypropylene (PP, Celgard 2400) film as the separator. A mixture of ethylene carbonate (EC) and dimethyl carbonate (DMC) (1:1 volume ratio) with $1 \mathrm{~mol} \mathrm{dm}^{-3}$ of $\mathrm{LiPF}_{6}$ was used as the electrolyte. Galvanostatic tests were carried out using a multi-channel battery cycler (Toyo System) with a potential ranging from $0.001 \mathrm{~V}$ and $3.000 \mathrm{~V}\left(\mathrm{vs} . \mathrm{Li}^{+} / \mathrm{Li}\right)$ at a rate of $0.2 \mathrm{C}\left(1 \mathrm{C}\right.$ rate $\left.=718 \mathrm{~mA} \mathrm{~g}^{-1}\right)$ for the electrodes of the nickel-based oxide films, and $0.05 \mathrm{~mA} \mathrm{~cm}^{-2}$ for the electrode made from the partially oxidized copper films. Cyclic voltammetry (CV) of the nickel based oxide electrodes was carried out over the potential ranging from $0.000 \mathrm{~V}$ to $3.000 \mathrm{~V}$ (vs. $\mathrm{Li}^{+} / \mathrm{Li}$ ) at a scan rate of $0.1 \mathrm{mV} \mathrm{s}^{-1}$.

\section{Results and Discussion}

It is important that the deposited film anneals under the appropriate thermal treatment form nickel-based oxides without fully oxidizing the copper substrate, which operates as a current collector for the path of electrons. A simple approach is to use the minimum annealing temperature possible to oxidize nickel but prevent copper from fully oxidizing. Some studies reported that approximately $300^{\circ} \mathrm{C}$ is the lowest temperature to form nickel oxides. ${ }^{14,15)}$ Therefore, the annealing temperature was set to this temperature.

Fig. 1 shows the XRD patterns of the nickel-based oxides and the degree of oxidation of the copper foils after annealing process. No peaks associated with nickel oxides or copper oxides were detected but strong copper $\left(\mathrm{Cu}^{0}\right)$ peaks were indicated in Fig. 1. It is possible that the nickel oxides and partially oxidized copper from the 


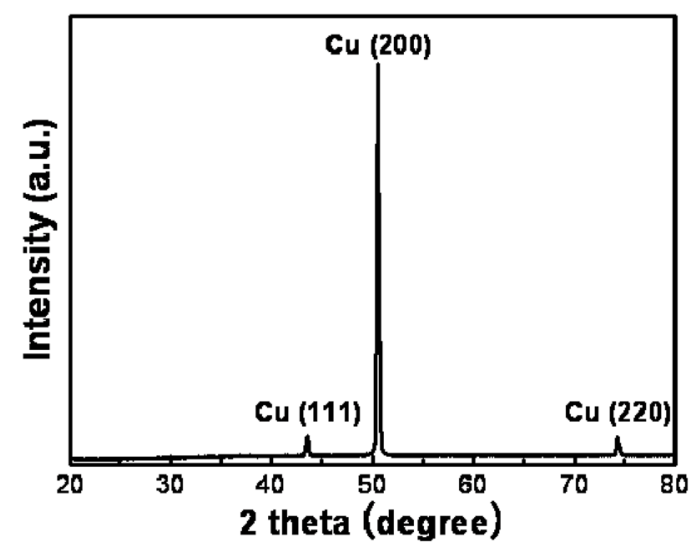

Fig. 1. X-ray diffraction patterns of the nickel-based oxide electrodes.

substrate formed during the annealing process have an amorphous structure. Moreover, the strong peaks for the copper foils show that the current collector is not fully oxidized under the heating condition. This means that the copper foils can be used as a substrate and current collector with sufficient ability to transfer electrons to the outer circuits due to the existence of metallic copper despite the presence of partially formed copper oxides.

Fig. 2 shows images of the sample surface. The FESEM images indicate that the sample surface was covered with a dense film that appears to increase in density with increasing number of dip-coating process. However, the cross-section images showed that the films had an porous structure, which can be used as electrode materials, on account of i) easy ion transfer, ii) good contact with the electrolytes, and iii) decrease in electrode stress when the films are going through the electrochemical reactions. Electron fluorescence spectroscopy (data not shown) was used for quantitative elemental analysis. These results show that the films are composed mainly of $\mathrm{Ni}$ and a few mole percent of $\mathrm{Cu}$. It is possible that $\mathrm{Cu}$ derived from copper foil acted as the current collector. During the heat treatment process, the copper on the foil diffuses to the deposited film. The diffused $\mathrm{Cu}$ can generate a new oxide phase that reacts with oxygen to form $\mathrm{CuO}$ and $\mathrm{Cu}_{2} \mathrm{O}$, i.e., the copper current collector is partially oxidized by the heat treatment process.

XPS was used to identify the constituents of the film. Fig. 3 shows that $\mathrm{NiO}$ and $\mathrm{CuO}$ are formed in the film. The nickel $2 p$ spectra show typical $\mathrm{NiO}$ peaks indicated in $856.2 \mathrm{eV}$ for triplet states and $873.8 \mathrm{eV}$ for singlet states. The spectra also show continuous satellite peaks
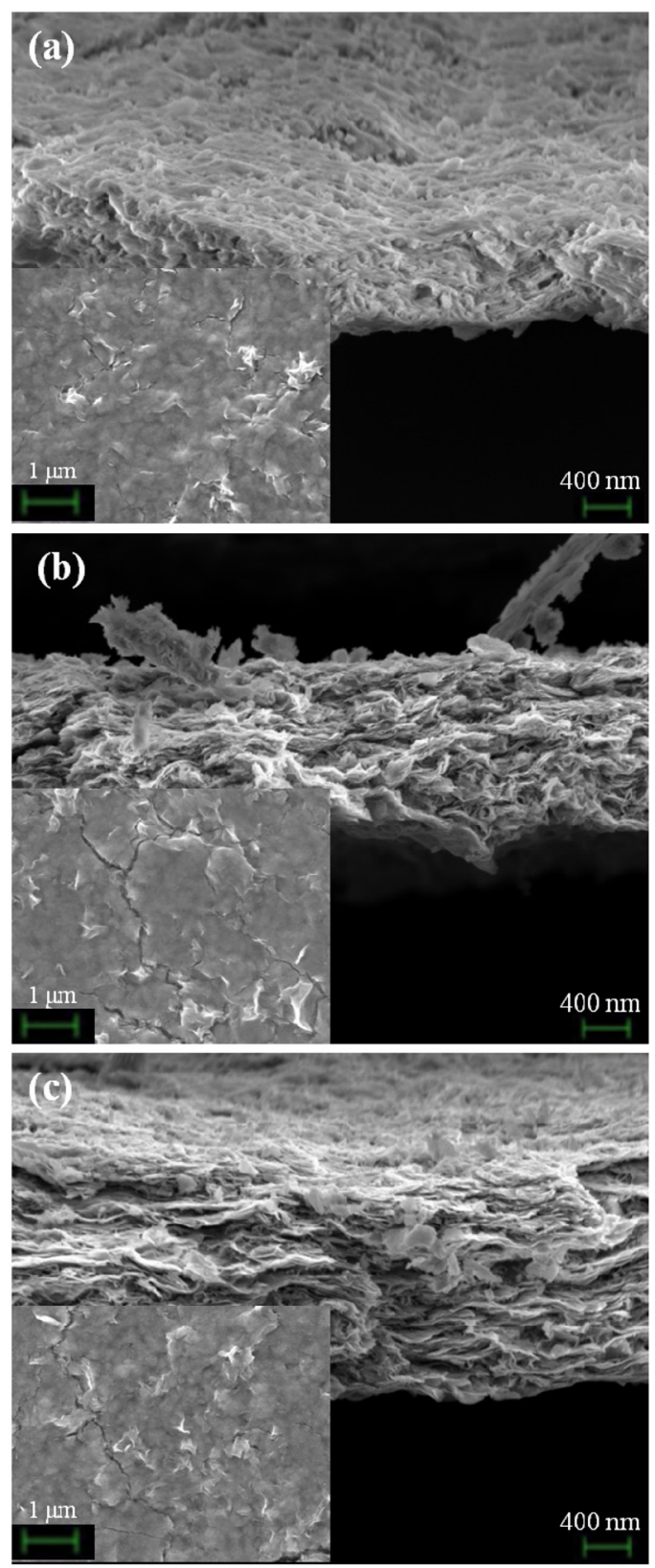

Fig. 2. FE-SEM images of the nickel-based oxide electrodes; (a) sample 1, (b) sample 2 and (c) sample.

that are approximately $5 \mathrm{eV}$ higher than the main peaks, which identify oxidized nickel $(\mathrm{NiO})$ by heat treatment. ${ }^{16)}$ As shown in Fig. 3(b), there are two peaks for the triplet and singlet states in $933.7 \mathrm{eV}$ and $953.8 \mathrm{eV}$, respectively. The peaks have a slightly higher binding energy than the copper metal peaks due to the difference 

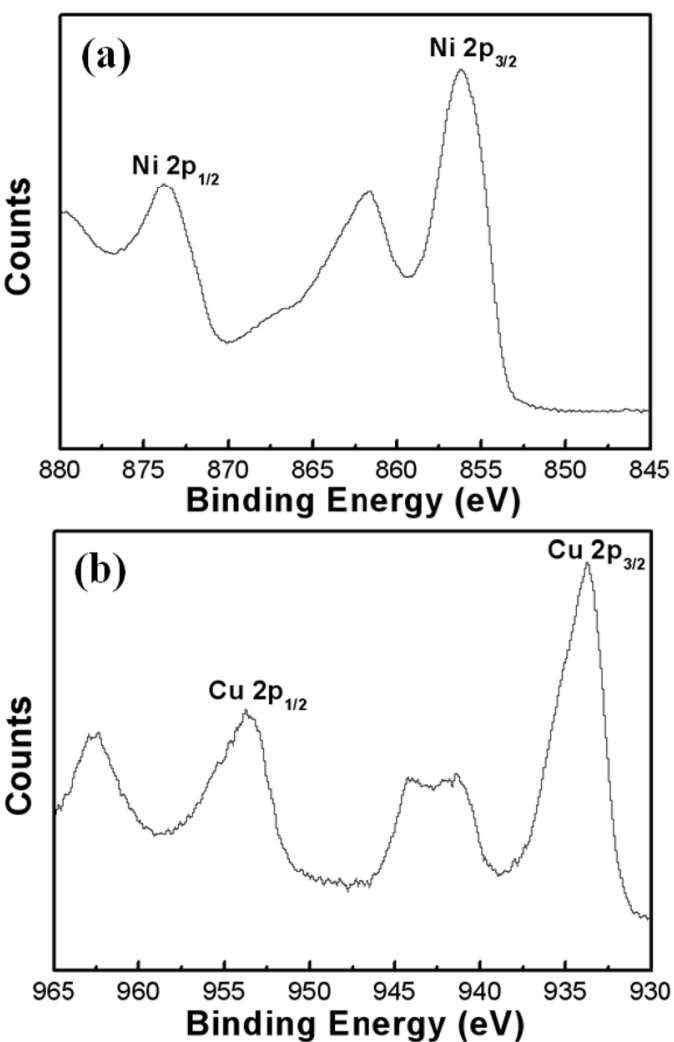

Fig. 3. X-ray photoelectron spectra of the nickel-based oxide electrodes; (a) Ni 2p, (b) Cu 2p spectra.

in chemical environment of copper oxides. ${ }^{17)}$ Moreover, the shake-up peaks in the spectrum indicate that the valence of copper is $2+$, i.e. $\mathrm{CuO} .{ }^{18,19)}$

Electrochemical half-cell tests were carried out using the electrodes of nickel-based oxides. Fig. 4(a) shows the first and the second galvanostatic curves of sample 2 between $0.001 \mathrm{~V}$ and $3.000 \mathrm{~V}\left(\mathrm{vs} . \mathrm{Li}^{+} / \mathrm{Li}\right.$ ) at a $0.2 \mathrm{C}$ rate. The figure shows a plateau from $0.9 \mathrm{~V}$ to $0.6 \mathrm{~V}$ in the initial discharge process. This plateau is slightly different from that reported elsewhere. ${ }^{11,20)}$ It is possible that the discrepancy is due to the film containing not only nickel oxides but also other materials, such as copper oxides and residues of the precursors, due to the low heat treatment temperature. However, the first charge and second discharge curves suggest a similar behaviour to that reported previously.

Fig. 4(b) shows the specific capacity of the charge process during the cycles. Samples 1 and 2 showed prominent capacity retention during cycles, i.e., the coulombic efficiency is about 1 for the proceeding charge/
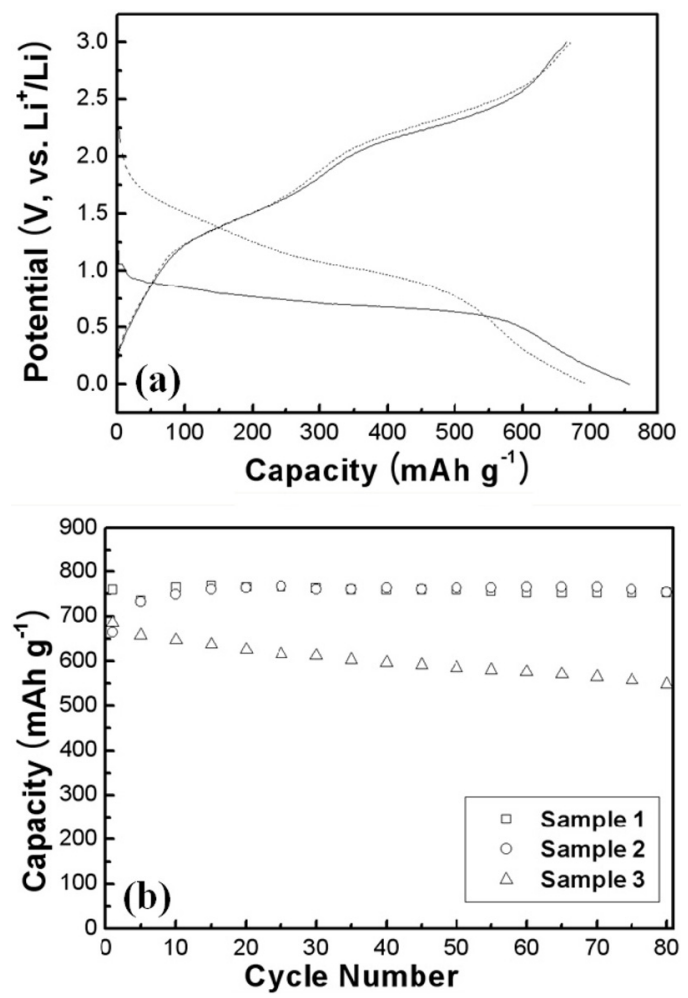

Fig. 4. Galvanostatic tests of the nickel-based oxide electrodes in the potential ranging from $0.001 \mathrm{~V}$ to $3.000 \mathrm{~V}$ $(\mathrm{Li}+/ \mathrm{Li})$ at 0.2 rate; (a) potential versus specific capacity curves of sample 2 (line: the $1^{\text {st }}$ cycle, dotted line: the $2^{\text {nd }}$ cycle) and (b) specific capacity during charge/discharge cycles.

discharge cycles. Such behaviours would mainly result from continuous oxidation of copper foils as shown in Fig. 7. In particular, some results show that samples 1 and 2 have a larger specific capacity than the theoretical value, $718 \mathrm{mAh} \mathrm{g}^{-1}$, which is based on two lithium ions reacting with nickel oxide, as mentioned earlier. It is possible that the excellent electrochemical behaviour was due to the structural properties of the films, as indicated by FE-SEM.

The origin of the surplus specific capacity was examined by cyclic voltammetry and will be reported in the next part. On the other hand, sample 3 showed a continuously decreasing specific capacity with respect to the progressing electrochemical redox reaction with a large irreversible reaction $\left(\sim 350 \mathrm{mAh} \mathrm{g}^{-1}\right)$, which is about two to three times higher than sample 1 and 2 , for the first cycle. It is possible that there is a critical thickness of deposited nickel-based oxides that affect the cyclic 
Table 1. The results of specific capacity and efficiency

\begin{tabular}{cccc}
\hline dimension $\left(\mathrm{mAh}^{-1}\right)$ & Initial capacity & $80^{\text {th }}$ capacity & Efficiency $^{*}$ \\
\hline Sample 1 & 759.63 & 752.94 & 0.99 \\
Sample 2 & 665.21 & 754.19 & $>1$ \\
Sample 3 & 685.39 & 549.15 & 0.80 \\
\hline
\end{tabular}

*Efficiency $=$ initial capacity/80th capacity

behavior of lithium ion batteries because the conductivity of electrodes decreases with increasing thickness of the active layer. Table 1 summarizes the retention of specific capacity after 80th charge/discharge cycles.

It is possible that the surplus capacity is caused by an electrochemical reaction of the solid electrolyte interface (SEI) and copper oxides, which was corroborated by the cyclic voltamogram (CV) shown in Fig. $6 .{ }^{21)}$ $\mathrm{CV}$ (Fig. 5) of sample 2 was performed after 80 charge/discharge cycles between $0.000 \mathrm{~V}$ and $3.000 \mathrm{~V}$ (vs. $\mathrm{Li}^{+} / \mathrm{Li}$ ) at $0.1 \mathrm{mV} \mathrm{s}^{-1}$. The oxidation peaks were observed at approximately $1.47 \mathrm{~V}$ and $2.31 \mathrm{~V}$. In accordance with the literature, ${ }^{22)}$ the former peak corresponds to the decomposition reaction of SEI materials, and the latter is catalytic reaction of nickel metal, i.e., $\mathrm{Li}_{2} \mathrm{O}+\mathrm{Ni} \rightarrow \mathrm{NiO}+2 \mathrm{Li}^{+}+2 \mathrm{e}^{-}$.

Unlike other CV curves of nickel oxide, it showed a large peak area in the decomposition of SEI materials. This means that a considerable number of electrochemical reactions occur when nickel metal decomposes SEI materials. The reduction peaks were located at approximately $0.90 \mathrm{~V}$ and $1.32 \mathrm{~V}$. The peak at $0.90 \mathrm{~V}$ indicates the electrochemical reaction of nickel oxide with lithium ions, $\mathrm{Li}^{+}+\mathrm{NiO}+\mathrm{e}^{-} \rightarrow \mathrm{Li}_{2} \mathrm{O}+\mathrm{Ni}^{22)}$ The peak at $1.32 \mathrm{~V}$ is different from the general $\mathrm{CV}$ curve of nickel

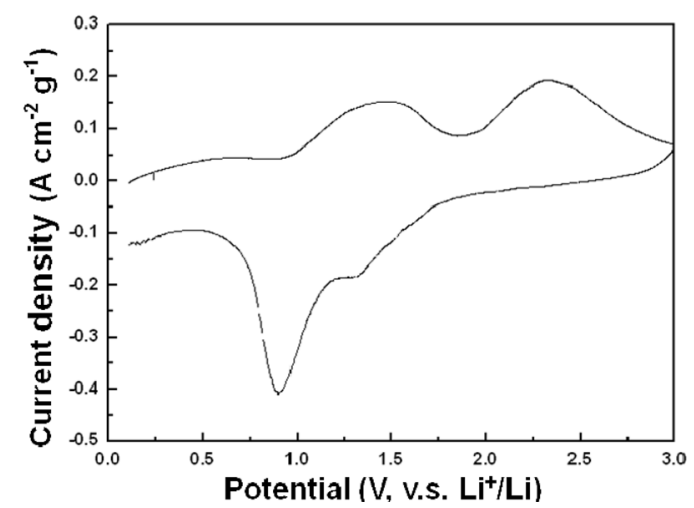

Fig. 5. Cyclic voltamograms of sample 2 after 80th charge/ discharge cycles in the potential range between $0.000 \mathrm{~V}$ and $3.000 \mathrm{~V}\left(\mathrm{Li}^{2} / \mathrm{Li}^{+}\right)$at $0.1 \mathrm{mV} \mathrm{s}^{-1}$. oxides. This was attributed to the reaction of copper oxides diffused from the current collector. The peak is consistent with the reduction of $\mathrm{Cu}^{2+}$ to $\mathrm{Cu}^{+}$. ${ }^{23}$ Therefore, the peak at $0.90 \mathrm{~V}$ indicates the decomposition of nickel oxides and copper oxides, which can produce additional capacity with stable cyclic performance.

In order to understand the additional capacity in detail, a partially oxidized metallic copper foil was prepared in a flow of compressed air for 3 hours at different temperatures $\left(100,150,200,250\right.$ and $300^{\circ} \mathrm{C}$, heating

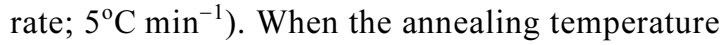
was $>300^{\circ} \mathrm{C}$, the copper foils became too wrinkled for them to be applied as electrodes for lithium ion batteries.

Fig. 6 shows surface images of the annealed copper foils at different temperatures. With increasing temperature, the surface of the annealed copper foils contained a layer of oxidized species. At $100^{\circ} \mathrm{C}$ (Fig. 6(a)), it is pos-
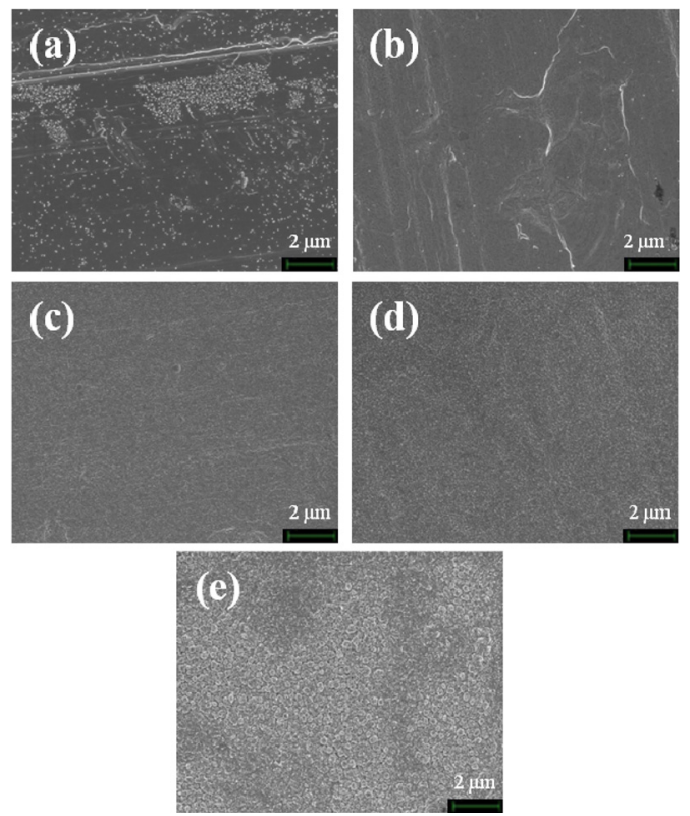

Fig. 6. FE-SEM images of partially oxidized copper foils; (a) $100^{\circ} \mathrm{C}$, (b) $150^{\circ} \mathrm{C}$, (c) $200^{\circ} \mathrm{C}$, (d) $250^{\circ} \mathrm{C}$ and (e) $300^{\circ} \mathrm{C}$. 

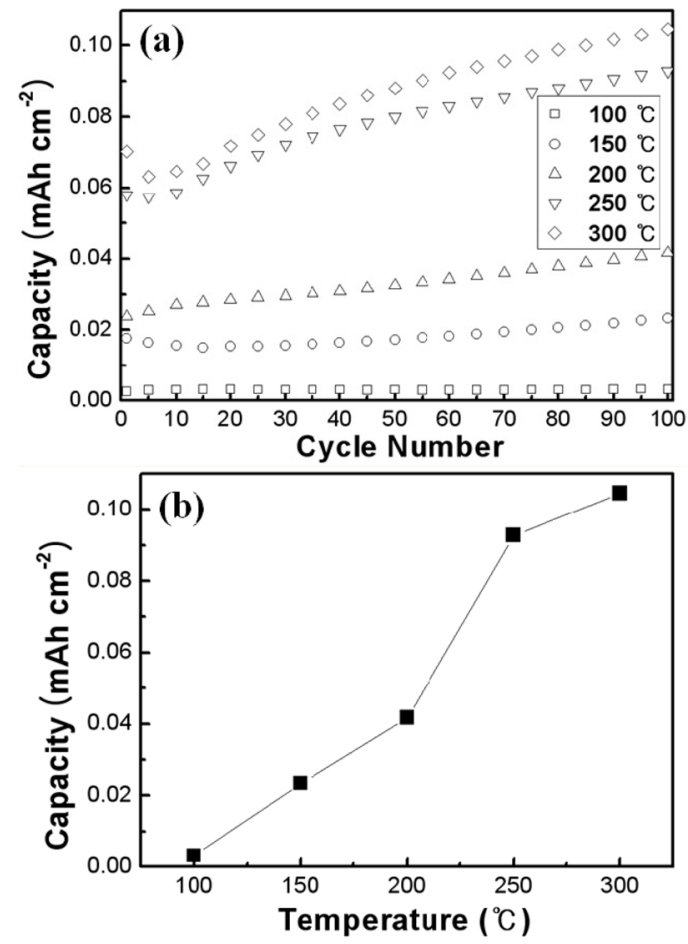

Fig. 7. Galvanostatic tests of partially oxidized copper foils; (a) specific capacity during charge/discharge cycles and (b) specific capacity after $100^{\text {th }}$ cycles with respect to temperatures.

sible that the film begins to grow islands from the existence of some spots on substrate. At temperatures between 150 and $200^{\circ} \mathrm{C}$, the spots spread over the entire substrate and coalescence (Fig. 6(b) and(c)). When the substrate temperature is $>200^{\circ} \mathrm{C}$, it is likely that copper oxides form continuous films with different grain sizes according to the substrate temperature. This suggests that the metallic copper foils form continuous films at temperature $>200^{\circ} \mathrm{C}$. (Fig. 6(d) and (e))

The half-cell tests were conducted to identify the electrochemical behaviours of partially oxidized copper foils. Fig. 7 shows that all the oxidized copper foils have stable capacity retention during 100 charge/discharge cycles. As shown in Fig. 6, it appears that the electrochemical reactivity toward lithium ions is divided in three categories: the formation of island regions with little specific capacity $\left(100^{\circ} \mathrm{C}\right)$, coalescence of island regions with intermediate capacity $(150$ and $200^{\circ} \mathrm{C}$ ) and a continuous film region with sufficient specific capacity, $>0.9 \mathrm{mAh} \mathrm{cm}{ }^{-2}$ after 100 cycles, $(250$ and $300^{\circ} \mathrm{C}$ ), although the oxidized copper foils forming continuous films have stable capacity retention at different annealing temperatures.

\section{Conclusion}

Film electrodes made from nickel-based oxides were deposited by chemical bath deposition of a sol-gel solution with subsequent annealing at low temperatures. During heat treatment, both the nickel related materials and copper foil used as both the substrate and current collector oxidized partially. The prepared electrode exhibited high specific capacity with the stable retention using anode materials of the lithium ion battery. The electrodes demonstrated high specific capacity with the stable retention of capacity as an anode material. Halfcell galvanostatic tests of the electrode showed that some of the nickel-based oxides exceeded their theoretical capacity after reacting with lithium. Partially oxidized copper foil is believed to be responsible for this unusual performance. An investigation of the electrochemical properties of oxidation of copper foils annealed at different temperatures showed that continuous films were formed at temperature $>200^{\circ} \mathrm{C}$, and showed high specific capacity compared to those annealed at low temperatures.

\section{Acknowledgment}

This research was supported by a grant from the Fundamental R\&D Program for Technology of World Premier Materials funded by the Ministry of Knowledge Economy, Republic of Korea

\section{References}

1. P.L. Taberna, S. Mitra, P. Poizot, P. Simon and J.-M. Tarascon, Nat. Mater, 5, 567 (2006).

2. Y. Yu, C.-H. Chen, J.-L. Shui and S. Xie, Angew. Chem. Int. Ed., 44, 7085 (2005).

3. J. Hassonun, S. Panero, P. Simon, P.L. Taberna and B. Scrosati, Adv. Mater, 19, 1632 (2007).

4. H.-J. Ahn, Y.-S. Kim, H.-S. Shim, C.-Y. Kim and T.-Y. Seong, Solid State Ionics, 176, 699 (2005).

5. Y. Yu, C.-H. Chen and Y.A. Shi, Adv. Mater, 19, 993 (2007).

6. H. Mukaibo, T. Sumi, T. Yokoshima, T. Momma and T. Osaka, Electrochem. Solid-State Lett., 6(10), A218 (2003).

7. H.-J. Ahn, K.-W. Park and Y.-E. Sung, Chem. Mater, 16, 1991 (2004).

8. J.J. Lee, S.H. Kim, S.H. Jee, Y.S. Yoon, W.I. Cho, S.J. 
Yoon, J.W. Choi and S.-C. Nam, J. Power Sources, 178, 434 (2008).

9. P. Poizot, S. Laruelle, S. Grugeon, L. Dupont and J.M. Tarascon, Nature, 407, 496 (2000).

10. E. Hosono, S. Fujihara, I. Honma and H. Zhou, Electrochem. Comm., 8, 284 (2006).

11. Y. Wang and Q.-Z. Qin, J. Electrochem. Soc., 149, A873 (2002).

12. Y.-N. Nuli, S.-L. Zhao and Q.-Z. Qin, J. Power Sources, 114, 113 (2003)

13. S.H. Park, J.W. Lim, S.J. Yoo, I.Y. Cha and Y.-E. Sung, Sol. Energy Mater. Sol. Cells, 99, 31 (2012).

14. W. Xing, F. Li, Z.-F. Yan and G.Q. Lu, J. Power Sources, 134, 324 (2004)

15. J. Li, R. Yan, B. Xiao, D.T. Liang and D.H. Lee, Energy \& Fuel, 22, 16 (2008).

16. C.D. Wagner, W.M. Riggs, L.E. Davis, J.F. Moulder and G. E. Muilenberg, Handbook of X-RAY Photoelectron Spec- troscopy, Perkin-Elmer Corp., Minnesota, U.S. (1978).

17. X.Y. Fan, Z.G. Wu, P.X. Yan, B.S. Geng, H.J. Li, C. Li and P.J. Zhang, Mater. Lett., 62, 1805 (2008).

18. J.F. Watts, J. Wolstenholme, An Introduction to Surface Analysis by X-ray Photoelectron Spectroscopy and Auger Electron Spectroscopy, John Wiley \& Sons Ltd., Sussex, U.K. (2003).

19. Z.S. Hong, Y. Cao and J.F. Deng, Mater. Lett., 52, 34 (2002).

20. X.H. Huang, J.P. Tu, C.Q. Zhang and J.Y. Xiang, Electrochem. Comm., 9, 1180 (2007).

21. S. Grugeon, S. Laruelle, R. Herrera-Urbina, L. Dupont, P. Poizot and J.-M. Trascon, J. Electrochem. Soc., 148, A285 (2001).

22. X.H. Huang, J.P. Tu, C.Q. Zhang, X.T. Chen, Y.F. Yuan and H. M. Wu, Electrochim. Acta, 52, 4177 (2007).

23. S.Q. Wang, J.Y. Zhang and C.H. Chen, Scripta Mater, $\mathbf{5 7 ,} 337(2007)$ 